\title{
Single dose oral analgesics for postoperative pain have few adverse events
}

\author{
Abstracted from \\ Moore RA, Derry S, Aldington D, Wiffen PJ. \\ Adverse events associated with single dose oral analgesics for acute postoperative pain in adults - \\ an overview of Cochrane reviews. Cochrane Database Syst Rev 2015; 10: CD011407. \\ Address for correspondence: RA Moore, Pain Research and Nuffield Department of Clinical Neuroscience, \\ University of Oxford, Pain Research Unit, Churchill Hospital, Oxfordshire, OX3 7LE, UK. E-mail: Andrew.moore@ndcn.ox.ac.uk
}

\section{Question: Does taking single dose oral analgesics cause any adverse events?}

Data sources The Cochrane Database of Systematic Reviews on the Cochrane Library.

Study selection All Cochrane reviews of RCTs between 1999 to 2015, conducted in adults examining the adverse events associated with single dose oral analgesics used for acute post-operative pain were considered.

Data extraction and synthesis Studies were searched, reviewed and assessed independently by two reviewers and standard data items extracted. Methodological quality was assessed using criteria adapted from AMSTAR (Assessing the Methodological Quality of Systematic Reviews).

Results Data from 39 Cochrane reviews of 41 different analgesics or analgesic combinations involving a total of 350 studies involving 35,000 adults were included. Most analgesics were tested in a narrow dose range. For most NSAIDs, paracetamol (acetaminophen), and combinations not containing opioids, the rates of adverse events were similar to that of placebos (NSAID $3 \%-44 \%$ vs $4-46 \%$; paracetamol $7-18 \%$ vs $6-16 \%$; combination $11-30 \%$ vs $6-48 \%$ ). However, for higher dosages, like $1000 \mathrm{mg}$ aspirin, $1000 \mathrm{mg}$ diflunisal, and opioids or drug combinations containing opioids, there was a statistically significant difference in the incidence of adverse events reported ( $\mathrm{NNH} 7.7(95 \% \mathrm{Cl} ; 4.8$ - 20) for $1000 \mathrm{mg}$ aspirin; $7.5(95 \% \mathrm{Cl} ; 4.8-17)$ for $1000 \mathrm{mg}$ diflunisal; 3.5-8.6 for opioids and combinations). Serious adverse events were rare, occurring at about 1 in 3,200.

Conclusions Despite ongoing problems with the measurement, recording and reporting of adverse events in clinical trials and in systematic reviews, the large amount of information available for single oral doses of analgesics provides evidence that adverse events rates are generally similar with active drug and placebo in these circumstances, except at higher doses of some drugs, and in combinations including opioids.

This paper is based on a Cochrane Review published in the Cochrane Library 2015, issue 10 (see www.thecochranelibrary.com for information). Cochrane Reviews are regularly updated as new evidence emerges and in response to feedback, and the Cochrane Library should be consulted for the most recent version of the review.

\section{Commentary}

This is an update of a Cochrane overview by the same authors in 2011, which considered both efficacy and adverse events. Not all studies reporting on efficacy reported on adverse events. Most studies did not report on specific adverse events, or define what the adverse events were. Different methods of ascertainment led to different results. Furthermore, adverse events were often reported on as a combination of all doses of a drug in a single analysis.

One electronic database was searched between 1999 and 2015 for this review. There was no restriction in language. All studies were randomised and double-blinded. The same author (RA Moore) was involved in all 39 systematic reviews included in this overview. Pain was assessed by participants using standard pain intensity and pain relief scales. There was a high level of clinical homogeneity since trials used consistent validated methods for measuring pain.

The majority of the studies involved third molar extractions in young patients. So the results may not be applicable to older or less healthy populations. Also, as evidence in this review came from single dose studies, the results may not be extrapolated to longer-term use, or people who are taking multiple drugs. Authors asked for cautions about the results, in that adverse event reporting rates are greatly influenced by the methods used to capture them ${ }^{1}$, since patient diaries yielded significantly more adverse effects than other forms of assessment. In addition, power of studies is affected where there is a limited number of participants and events ${ }^{2}$.

Authors reported no publication bias. Most studies were sponsored or conducted by manufacturers, but there was no industry bias as specific analyses have been performed to ensure that ${ }^{3}$. Serious adverse events were rare, occurring about 1 in 3,200, and not all of them were clearly related to treatment.

Yin J Wong

New York University, College of Dentistry, New York, USA

1. Edwards JE, McQuay HJ, Moore RA, Collins SL. Reporting of adverse effects in clinical trials should be improved: lessons from acute postoperative pain. I Pain and Symptom Manage 1999; 18: 427-437

2. Moore RA, Derry S, Aldington D, Wiffen PJ. Single dose oral analgesics for acute postoperative pain in adults - an overview of Cochrane reviews. Cochrane Database Syst Rev 2015; 9: Art. No. CD008659.

3. Barden J, Derry S, McQuay HJ, Moore RA. Bias from industry trial funding? A framework, a suggested approach, and a negative result. Pain 2006; 121: 207-218.

Evidence-Based Dentistry (2016) 17, 83. doi:10.1038/sj.ebd.6401188 